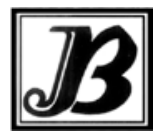

J. Bio-Sci. 27: 01-10, 2019

ISSN 1023-8654 http://www.banglajol.info/index.php/JBS/index DOI: https://doi.org/10.3329/jbs.v27i0.44666

\title{
GENDER DISPARITY IN NUTRITIONAL STATUS AMONG UNDER FIVE CHILDREN IN RAJSHAHI CITY, BANGLADESH
}

\author{
K Yeasmin ${ }^{1}, \mathrm{KMS}_{\text {Islam }}^{2}$ and T Yeasmin ${ }^{3 *}$ \\ IInstitute of Biological Sciences, University of Rajshahi, Bangladesh \\ ${ }^{2}$ Rajshahi Medical College Hospital, Rajshahi, Bangladesh \\ ${ }^{3}$ Department of Biochemistry and Molecular Biology, University of Rajshahi, Bangladesh
}

\begin{abstract}
Girls face discrimination from the moment of her birth. Different underlying factors are responsible for this disparity. Though in recent decades, there is a significant advance in gender disparity, it is still prevalent in different aspect of life throughout the world. Yet a wide level of disparity still exists, whether implicit or explicit, in nutrition and child cares both in the rural and urban areas. Thus, the aim of the study was to determine the gender disparity in nutritional status among under five children in Rajshahi City, Bangladesh. A community based multi-stage cross-sectional study were accomplished for collecting anthropometric and household socio-demographic data of under-five $(36 \leq$ age $\leq 59)$ children to assess gender disparity on nutritional status in Rajshahi City, Bangladesh. It was performed during the period March 2017 to September 2017. Simple random sampling was used to select children from households by applying multistage sampling technique. Data were analyzed using WHO anthro 2005 software (WHO, Geneva, Switzerland) and Statistical Package for Social Sciences IBM (SPSS) version 22.0. A value of $p<0.05$ was regarded as statistically significant in the analysis. Under five 371 girls with mean age $47.26 \pm 8.33$ months and 366 boys with mean age $48.28 \pm 7.75$ months were participated in this study. No failure in composite anthropometry/normal healthy boys and girls were found $46 \%$ and $36 \%$ respectively. The prevalence of moderate underweight, stunting and wasting among girls were $23.5 \%, 27.5 \%$ and $14.6 \%$ respectively, whereas, among boys $22.7 \%, 25.4 \%$ and $9.8 \%$ respectively. Deficiency of energy intake, insufficiency of macro and micro nutrients increase the chance of suffering protein-energy malnutrition, nutritional disorders among girls, compared to boys. Aggregating social development and intervention program of Government may help to reduce gender disparity and improve the nutritional status of overall all children.
\end{abstract}

Key words: Cross-sectional study, Disparity, Gender, Nutritional status, Rajshahi city

\section{Introduction}

Malnutrition is a sustaining problem in many of the developing countries and one of the major causes of morbidity and mortality among children under five years of age (Ezzati et al. 2002). Under-nutrition is a threatening root of infant and young child mortality by reducing life span (UNDP 2008) and therefore, associated with more than half of all deaths of children worldwide. The study identified several biological, social, cultural, economic, and morbidity factors as the determinants of child malnutrition such as age of child, birth weight, duration of breastfeeding, gender of household head, residence, type of house, toilet facility, parents education, child caretaker, milk and dairy products, staple food, and incidence of cough and diarrhea (Alom et al. 2009). The consequence of malnutrition on children are not only limited to physical

*Author for correspondence: yeasmin_bio@yahoo.com 
health, but also extend to mental, social, emotional as well as spiritual wellbeing and could be conveyed from one generation to another, creating a vicious cycle (McGregor 2007).

Child's nutritional status are influenced by mainly two dominating factors such as, the child's dietary intake and all the other elements that contribute to the overall health status (Ndiku et al. 2011). These two factors are predisposed by food security, adequate care for mothers and children and a proper health environment at the household level (Smith and Haddad 2000).

Gender discrimination and food insecurity are widespread concern according to FAO (2012) gender disparity in quantity and quality of food intake may result to under-nutrition mainly in settings where the boy child is still considered more important than the girl child (Dey and Chaudhuri 2008). Various studies observed that Under-nutrition during childhood actually means that girls are unable to reach their full growth potential, and deprived on in their lives in the next time not only in terms of health, but also regarding their enrollment and continuation in education and in the job market and lifelong consequence of malnutrition are handed over the future generation, creating malicious spiral of female deprivation (De Rose et al. 2000, Alam 2012). Gender inequality affects nutritional status due to intra household allocation of resources has been consistently allocated in several parts of South Asia (Moestue et al. 2004, Dancer et al. 2008). In the household level gender bias and cultural power differences may have a negative impact on women's food and nutrition security, decision-making processes, and responsibilities for producing, earning, purchasing, preparing, and consuming food (De Schutter 2013). We supposed that if boys and girls under 5 years old were treated in the same manner, cared for and nourished in the same way, their anthropometric status should be alike. Dissimilarities in their anthropometric measurement can be ascribed to discriminations in diet and health care. Reduction of hunger and malnutrition are partially accelerated by economic growth, however, thrives of gender discrimination and biased behavior against the half of the population in a country may ensure a little hope of removing malnutrition and hunger in total. UN's Department of Economic and Social Affairs (UNDESA) reported that in India, a under five girl $75 \%$ more chance to die than a boy, converting India, an extreme case of gender disparity in childhood mortality and morbidity pattern. Bangladesh is the most nearest neighbor country of India. Thus, the aim of the study was to determine the gender disparity in nutritional status among under five children in Rajshahi City, Bangladesh.

\section{Materials and Methods}

A community based multi stage cross-sectional study were accomplished for collecting anthropometric and household socio-demographic data of under-five $(36 \leq$ age $\leq 59)$ children to assess gender disparity on nutritional status in Rajshahi city, Bangladesh. It was performed during the period March 2017 to September 2017. Rajshahi city consists of 30 wards. We selected randomly 20 wards. A list of households with under five children was collected from ward councilor offices. Nearly fifty households from each ward with under five children were primarily designated for survey. Source population were children of aged 36 months to 59 months, living in the Rajshahi city at least six months and study population were children with 36 - 59 months randomly selected and included in the study. The household heads were not agreed to participate in the study or severe illness of mother or child, were excluded from the study. The sample size was calculated using a single proportion formula by using $41.4 \%$ of prevalence of malnutrition in Rajshahi city, $95 \%$ confidence interval $(\mathrm{Cl})$, marginal of error $5 \%$ and $10 \%$ non-response rate were added to the total sample size was computed.

A Z-value of 1.96 used at $95 \% \mathrm{Cl}$ and $d$ of $5 \%$. ( $n=$ sample size, $p=$ prevalence, $d=$ margin of error).

$n=Z^{2} p(1-p)=(1.962 \times 0.414)(1-0.414)=373$

$d^{2} 0.052$. 
So by considering for non-response ( $10 \%$ contingency) $n=(373+37)=410$, and again multiplied by design effect 2, the final sampling size was 820 children. However, for the disapproval of participating in the study of 83 parents, we had included 737 children as study population.

Multistage sampling technique applied and finally, simple random sampling was used to select children from households. From 30 wards, 20 wards selected by simple random sampling (lottery method). Study participants/households/mothers were allocated to selected wards by proportional allocation method and from each selected ward, study participants were selected by simple random sampling (using table of random numbers).

Pre and post tested semi structured questionnaires were used to obtain data on socio-demographic characteristics of the households of the children. The parents of the target child responded to the interview questions. A household dietary diversity questionnaire recommended by FAO (2010) was adopted and improved for this study. The recall included foods from 16 food groups which are Cereals; Vitamin A rich vegetables and tubers; White roots and tubers; Dark green leafy vegetables; Other vegetables; Vitamin A rich fruits; Other fruits; Organ meat; Flesh meat; Eggs; Fish; Pulses/Legumes, nuts and seeds; Milk and milk products; Oils and fats; Sweets and sugar and condiments and spices. 16 food groups according to food consumption score (FCS) are regrouped into 7 food groups by applying simple adding frequencies. Parents were asked to make list all of the food, taken by their child last 24 hours before the survey. Hence, consumed macro and micro nutrients were calculated by using Nutri survey for Windows (2007) by inputting the collected data.

\section{Anthropometric measurements}

Age of the study population was assessed by birth registration card or immunization card. Measurements of weight and height were obtained with digital machine in accordance with standard procedure (Lohman et al. 1988). Weight measurement was performed by a digital weight machine at three times by wearing minimal clothes and bare footed and the average was calculated and recorded with standard error in kilogram. Height was measured using the seca vertical height scale standing upright in the middle of the board to the nearest $0.1 \mathrm{~cm}$. The child's head, shoulders, buttocks, knees, and heels touch the vertical board and the average was calculated and recorded with standard error. Head circumference $(\mathrm{HC})$ of children were measured by the standard anthropometric procedures (Hall et al. 2007) using a flexible, non-stretch plastic coated tape, which was passed over the supracilliary ridges in front and maximum occipital protuberance at the back in such a way as to get maximum $\mathrm{HC}$. The measurements were taken to the nearest $0.1 \mathrm{~cm}$.

\section{Outcome measures}

Weight, height, head circumference and age data were used to analyze z-scores of the four different nutritional indicators by the guidance of the newly published WHO growth curve. These indicators were underweight defined as weight-for-age (W/A) z-score $<-1$, wasting defined as weight-for-height $(W / H) z$-score $<-1$, stunting defined as height-for-age $(H / A) z-s c o r e<-1$ and malnourishment defined as head circumference for age (HCA) z-score <-2 (WHO, 2012).

Data were analyzed using WHO anthro 2005 software (WHO, Geneva, Switzerland). The WHO anthro 2005 program considers z-score values for W/H of $<-5$ as outliers, on the other hand, for $\mathrm{H} / \mathrm{A}$ and W/A, it identifies $z$-score values $<-6$ as outliers. Data on socio-demographics of the caregivers was entered and analyzed using Statistical Package for Social Sciences IBM (SPSS) version 22.0. A value of $p<0.05$ was regarded as statistically significant in the analysis and food consumption data was entered into Nutri-survey for Windows (2007) for calculations of quantity, that was converted to gram/microgram equivalents. Recommended daily 
intake of nutrients for pre-school children was assessed by the reference of MC William (1980). Microsoft Word and Microsoft Excel were used for tabular charts and graphical representation.

\section{Results and Discussion}

\section{Age and gender wise distribution of children}

Table 1 represented that a total 737 under five children of Rajshahi city, Bangladesh took part in this study. Three hundred and seventy one girls with mean age $47.26 \pm 8.33$ months and three hundred and sixty six boys with mean age $48.28 \pm 7.75$ months were participated in this study. There was a progressive increase of children with increase of age.

Table 1. Distribution of under 5 year's children in Rajshahi city according to gender

\begin{tabular}{c|c|c}
\hline Age category in months & Boys (N) & Girls (N) \\
\hline $36-47$ & 173 & 181 \\
\hline $48-59$ & 193 & 190 \\
\hline Total & 366 & 371 \\
\hline
\end{tabular}

Prevalence of composite index of anthropometric failure (CIAF) (gender wise) in Rajshahi city, Bangladesh

Fig. 1 and 2 showed that distribution of composite index of anthropometric failure (CIAF) among boys and girls.

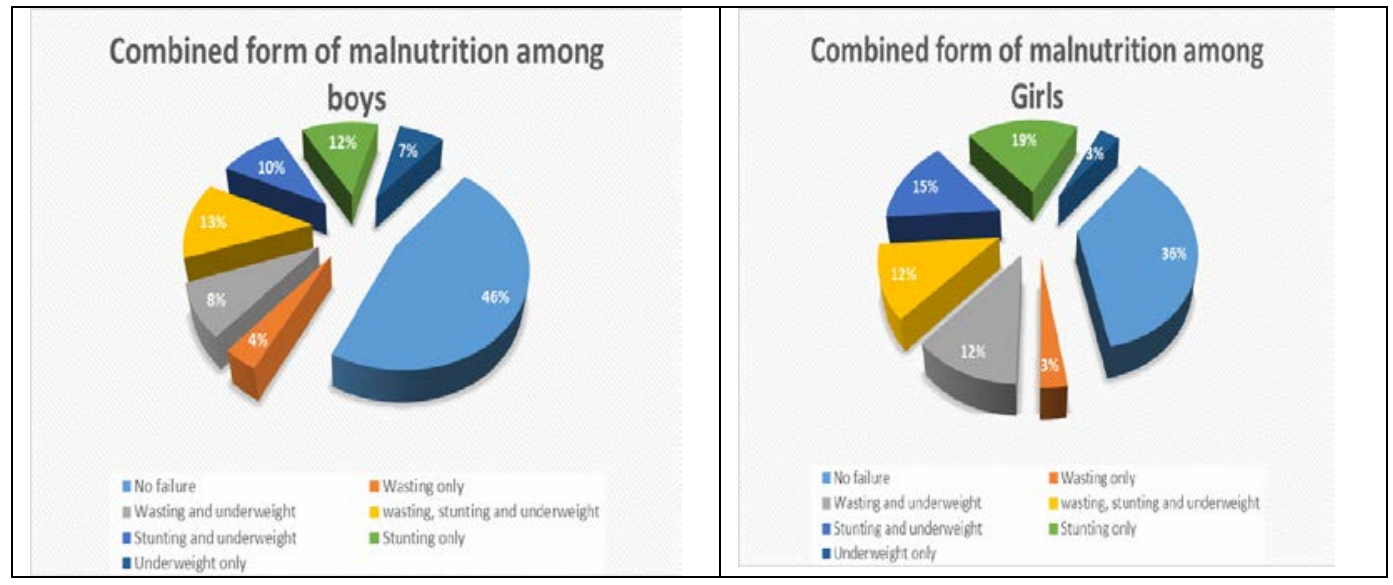

Fig. 1. Proportional distribution of CIAF of boys among under-five children in Rajshahi city.
Fig. 2. Proportional distribution of CIAF of girls among under-five children in Rajshahi city.

The CIAF can be used to determine the synergistic impact on health and mortality of composite combinations of stunting, wasting and underweight and interaction between disease, mortality and different combinations of anthropometric failure. Children with multiple anthropometric failures are more likely to be ill and the mortality rate will be increasing proportionately (Svedberg 2000). Those with a triple failure carrying the greatest possibilities of morbidity (and potentially mortality) risk. In our empirical study, no failure in composite anthropometry / normal healthy boys and girls were found $46 \%$ and $36 \%$ respectively. Therefore, 
it was clearly detected that girls were more vulnerable situation in nutritional status than boys. Approximately similar outcomes shown by Seetharaman (2007), where $31.4 \%$ of the children studied were normal/no failure; $68.6 \%$ were in a state of "Anthropometric Failure".

Comparison of the distribution of z-score of height-for-age, weight-for-age, weight-for-height, head circumference - for - age of Rajshahi under-five children to WHO child growth standards

From Fig. 3(a-d), we had perceived that comparison of the distribution of z-score of W/H, W/A, H/A, HC/A with WHO growth standards between female children (girls) and male children (boys). Results revealed the susceptibility of girls of being malnourished were comparatively higher than boys. Though, it was well recognized from the following figures that all children in Rajshahi city were more in recessive position compared to WHO growth standards.

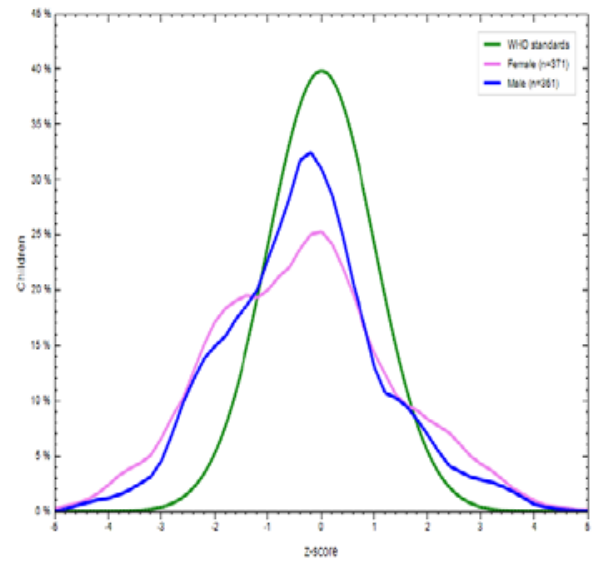

Fig. 3a. Comparison of the distribution of z-score for weight-for-height of Rajshahi under-five children to WHO child growth standards.

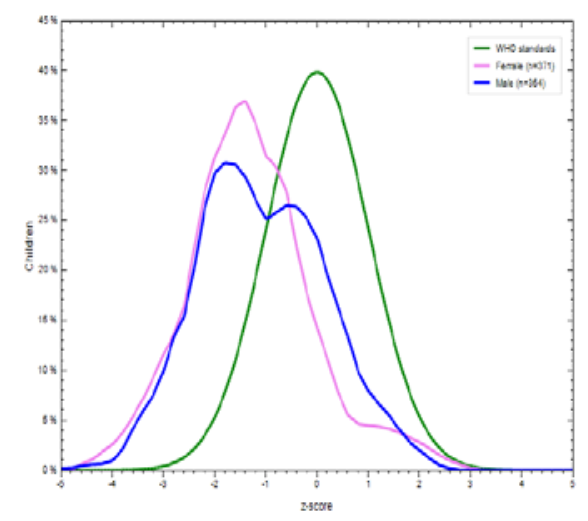

Fig. 3c. Comparison of the distribution of z-score of height-for-age of Rajshahi under-five children to WHO child growth standards.

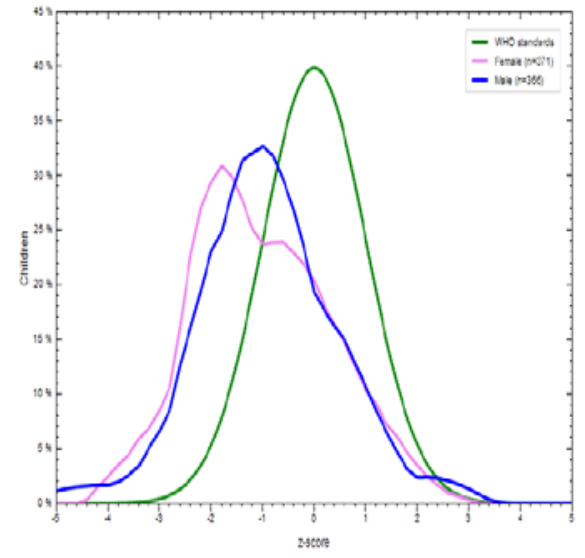

Fig. 3b. Comparison of the distribution of z-score for weight-for-age of Rajshahi under-five children to WHO child growth standards.

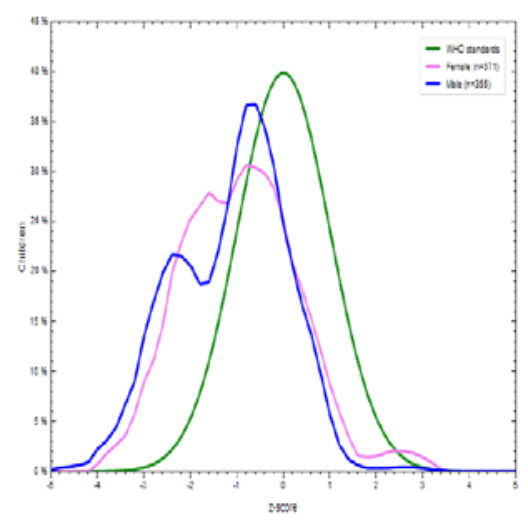

Fig. 3d. Comparison of the distribution of z-score of head circumference-for-age of Rajshahi underfive children to WHO child growth standards. 


\section{Comparison of mean height, weight and $\mathrm{HC}$ between boys and girls}

The height of boys in average were $2.95 \mathrm{~cm}$ greater than the height of girls, similarly the weight of boys in an average were $0.86 \mathrm{~kg}$ greater than the weight of girls, finally the head circumference of boys were $0.63 \mathrm{~cm}$ larger in average than the $\mathrm{HC}$ of girls. The comparison of height, weight and $\mathrm{HC}$ between boys and girls were statistically significant. In all cases, standard deviation of boys was higher than SD of girls, which proved that the data of boys, compared to girls were more dispersed. Mean proportional test were carried out by the guidance of Altman (1991).

Table 2. Comparison of mean height, weight and $\mathrm{HC}$ between boys and girls in Rajshahi

\begin{tabular}{|c|c|c|c|c|c|c|c|c|c|}
\hline Gender & $\begin{array}{l}\text { Mean } \\
\text { height }\end{array}$ & $95 \% \mathrm{Cl}$ & $p$-value & $\begin{array}{c}\text { Mean } \\
\text { weight }\end{array}$ & $95 \% \mathrm{Cl}$ & $p$-value & Mean $\mathrm{HC}$ & $95 \% \mathrm{Cl}$ & $p$-value \\
\hline 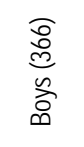 & 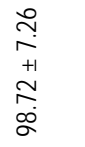 & \multirow{2}{*}{ 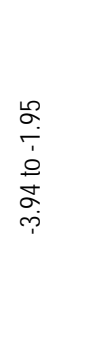 } & \multirow{2}{*}{ ठㅇㅇㅇ. } & \begin{tabular}{l}
$\vec{D}$ \\
$\underset{\sim}{+}$ \\
+1 \\
$\infty$ \\
$\infty$ \\
\multirow{J}{*}{}
\end{tabular} & \multirow{2}{*}{$\begin{array}{l}\text { fo } \\
0 \\
\dot{0} \\
\stackrel{0}{0} \\
\stackrel{2}{7} \\
\rightarrow\end{array}$} & \multirow{2}{*}{ ठ্口̊ } & 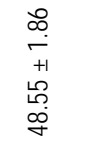 & \multirow{2}{*}{$\begin{array}{l}0 \\
0 \\
0 \\
1 \\
0 \\
0 \\
0 \\
0\end{array}$} & \multirow{2}{*}{ 官 } \\
\hline 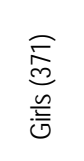 & 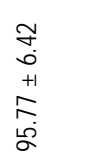 & & & 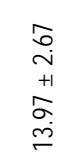 & & & 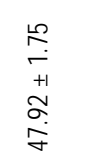 & & \\
\hline
\end{tabular}

Malnutrition prevalence in Rajshahi city between boys and girls

The prevalence of malnutrition was significantly greater in girls than boys as observed in all the anthropometric indicators (Table 3). The prevalence of moderate underweight, stunting and wasting among girls were 23.5, 27.5 and 14.6 respectively, whereas, among boy 22.7, 25.4 and 9.8 respectively. On the other hand, $8.6 \%, 7.8 \%$ and $5.9 \%$ of the girls severely underweight, stunted and wasted, respectively, compared with $5.7 \%, 4.9 \%$ and $7.0 \%$ of the boys. This results to be comparatively more malnourished to girls were assumed that low educational status of mother, poor dietary diversity, continual attacked by diseases as well as discouraging mentality and social negligence towards girls. Similar observation was detected by the study Harris and BarbarA (1990) shown that the household dietary intake of under five children in the sub-continent were worsen among girls in compared to boys. Ndiku (2011), found in his study that the proportion of severely and moderately malnourished were comparatively higher among girls than boys. A study in India by Dey and Chaudhuri (2008), reporting 55.9\%, 51.4\% and $42.3 \%$ of the girls underweight, stunted and wasted, respectively, compared with $46.6,40.5$ and $35.3 \%$ of the boys, contribution for this differences were to be that girls have less access to nutrition, physical and mental health care, and education. 
Table 3. Malnutrition prevalence in number and percentage for children under 5 years in Rajshahi city stratified by gender

\begin{tabular}{lcc}
\hline Anthropometric Indicators & Boys & Girls \\
\hline Mild (<-1 SD) & & \\
Weight-for-age (Underweight) & $38(10.4 \%)$ & $35(9.4 \%)$ \\
Height-for-age (Stunting) & $21(5.7 \%)$ & $40(10.8 \%)$ \\
Weight-for-height (Wasting) & $34(9.3 \%)$ & $36(9.7 \%)$ \\
Moderate (<-2SD) & & \\
Weight-for-age (Underweight) & $83(22.7 \%)$ & $87(23.5 \%)$ \\
Height-for-age (Stunting) & $93(25.4 \%)$ & $102(27.5 \%)$ \\
Weight-for-height (Wasting) & $36(9.8 \%)$ & $54(14.6 \%)$ \\
Head circumference-for-age (malnourished) & $97(26.5 \%)$ & $130(26.9 \%)$ \\
Severe (<-3SD) & & $32(8.6 \%)$ \\
Weight-for-age (Underweight) & $21(5.7 \%)$ & $29(7.8 \%)$ \\
Height-for-age (Stunting) & $18(4.9 \%)$ & $22(5.9 \%)$ \\
Weight-for-height (Wasting) & $26(7 \%)$ & $53(14.3)$ \\
Head circumference-for-age (malnourished) & $33(9 \%)$ & \\
\hline
\end{tabular}

\section{Dietary diversity between boys and girls in Rajshahi city}

Poor dietary diversity is a precarious problem in developing countries; conversely, a high dietary diversity has also been positively correlated with improvement in the nutritional status of children, seen by Kennedy (2007). Steyn (2005) shown that dietary diversity is an indicator of the quality of diet, particularly the intake of micronutrients among young children. In Rajshahi City, our study revealed that in contrast to boys, girls were habituated to poor dietary diversity (<4.5). Rich dietary diversity consumed double by boys than girls. Like many developing countries, food insecurity and gender discrimination are widespread issue in Bangladesh.

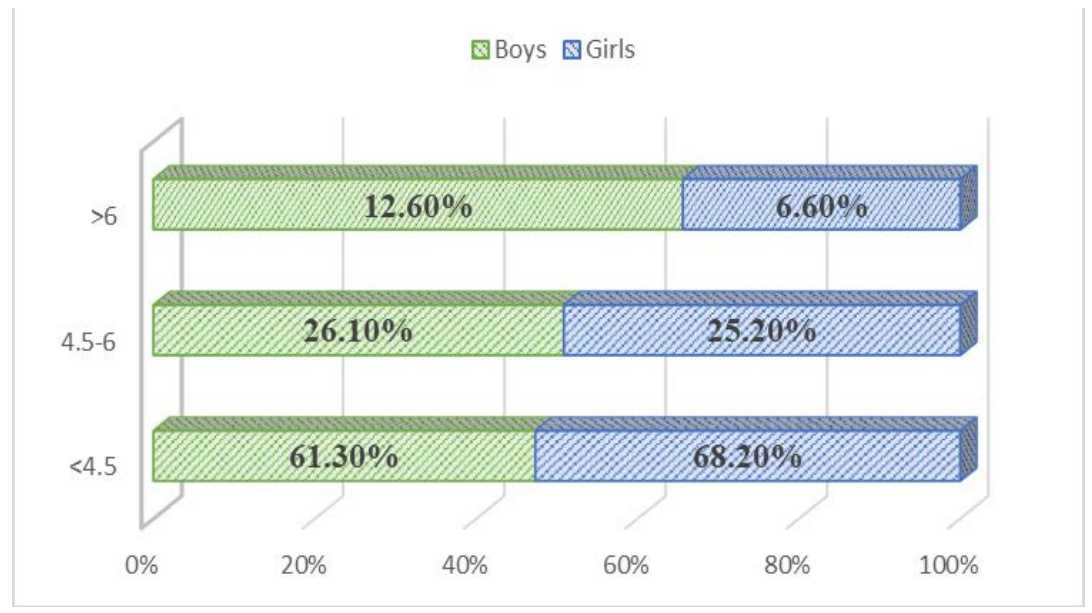

Fig. 4. Dietary diversity among boys and girls in Rajshahi city. 


\section{Nutritional adequacy of the children's diet}

Table $4 \mathrm{a}$ and $4 \mathrm{~b}$ represented that intake of required energy, protein, other micronutrients of boys were less than that of girls. Therefore, Deficiency of energy intake, insufficiency of macro and micro nutrients increased the chance of suffering protein-energy malnutrition, nutritional disorders among girls, compared to boys. Girl's deprivation in terms of nutrition and healthcare rebounds on society as a whole in the form of ill-health, reduced productivity not only for themselves, but also for their future generation (Osman and Sen 2003, World Bank 2006).

Table 4a. Nutrient intake by 3 years old boys and girls in Rajshahi city

\begin{tabular}{|c|c|c|c|c|c|c|}
\hline \multirow{3}{*}{ Nutrients } & \multicolumn{3}{|c|}{ Boys } & \multicolumn{3}{|c|}{ Girls } \\
\hline & \multicolumn{2}{|c|}{ Nutrient Intake range } & \multirow[t]{2}{*}{ Mean \pm SD } & \multicolumn{2}{|c|}{ Nutrient Intake range } & \multirow[t]{2}{*}{ Mean \pm SD } \\
\hline & Minimum & Maximum & & Minimum & Maximum & \\
\hline Energy (kcal) & 897.00 & 1700.0 & $1316.17 \pm 237.51$ & 760.00 & 1700.00 & $1275.33 \pm 226.67$ \\
\hline Protein in gm & 5.00 & 23.00 & $9.8 \pm 3.81$ & 3.00 & 18.00 & $8.95 \pm 3.07$ \\
\hline Vit. A $(\mu \mathrm{g})$ & 99.00 & 345.70 & $232.73 \pm 66.69$ & 99.00 & 300.00 & $210.99 \pm 76.97$ \\
\hline Vit. E (mg) & 2.00 & 8.70 & $5.30 \pm 1.57$ & 2.00 & 6.50 & $4.61 \pm 1.61$ \\
\hline Vit. B1 (mg) & 0.00 & 0.90 & $0.173 \pm 0.11$ & 0.0 & 0.40 & $0.174 \pm 0.106$ \\
\hline Vit. B2 (mg) & 0.300 & 0.900 & $0.68 \pm 0.181$ & 0.3 & 0.800 & $0.614 \pm 0.189$ \\
\hline Vit. B6 (mg) & 0.40 & 0.90 & $0.78 \pm 0.177$ & 0.40 & 0.90 & $0.78 \pm 0.172$ \\
\hline Folic acid $(\mu \mathrm{g})$ & 32.00 & 107.80 & $85.68 \pm 22.46$ & 32.00 & 107.80 & $85.75 \pm 23.14$ \\
\hline Vit. C (mg) & 21.00 & 45.00 & $36.82 \pm 5.71$ & 21.00 & 45.00 & $35.98 \pm 6.53$ \\
\hline Calcium (mg) & 334.00 & 800.00 & $595.91 \pm 197.47$ & 334.00 & 800.00 & $557.66 \pm 198.94$ \\
\hline Iron (mg) & 3.20 & 15.00 & $9.41 \pm 3.99$ & 3.20 & 15.00 & $7.77 \pm 4.17$ \\
\hline Zinc (mg) & 4.30 & 10.00 & $8.38 \pm 2.20$ & 4.30 & 10.00 & $8.014 \pm 2.21$ \\
\hline
\end{tabular}

Table 4b. Nutrient intake by 4-5 years old boys and girls in Rajshahi city

\begin{tabular}{lcccccc}
\hline \multirow{2}{*}{ Nutrients } & \multicolumn{3}{c}{ Boys } & \multicolumn{3}{c}{ Girls } \\
\cline { 2 - 5 } & \multicolumn{2}{c}{ Nutrient intake range } & Mean \pm SD & Nutrient intake range & Mean \pm SD \\
\cline { 2 - 3 } \cline { 5 - 6 } & Min. & Max. & & Min. & Max. \\
\hline Energy (Kcal) & 860.00 & 1800.00 & $1310.54 \pm 365.67$ & 780.00 & 1800.00 & $1290.05 \pm 344.9$ \\
Protein in gm & 5.00 & 43.00 & $12.92 \pm 10.78$ & 4.00 & 43.00 & $11.16 \pm 7.81$ \\
Vit. A $(\mu \mathrm{g})$ & 99.00 & 400 & $276.71 \pm 88.70$ & 99.00 & 400.00 & $264.58 \pm 92.56$ \\
Vit. E $(\mathrm{mg})$ & 2.00 & 6.00 & $3.98 \pm 1.26$ & 2.00 & 7.00 & $3.90 \pm 1.18$ \\
Vit. B1 $(\mathrm{mg})$ & 0.00 & 1.20 & $0.64 \pm 0.347$ & 0.00 & 1.20 & $0.588 \pm 0.357$ \\
Vit. B2 $(\mathrm{mg})$ & 0.300 & 1.300 & $0.786 \pm 0.294$ & 0.200 & 1.300 & $0.737 \pm 0.263$ \\
Vit. B6 $(\mathrm{mg})$ & 0.40 & 1.30 & $0.75 \pm 0.22$ & 0.40 & 1.30 & $0.75 \pm 0.208$ \\
Folic acid $(\mu \mathrm{g})$ & 45.00 & 233.00 & $138.30 \pm 53.96$ & 45.00 & 200.00 & $130.31 \pm 54.07$ \\
Vit. C $(\mathrm{mg})$ & 21.00 & 45.00 & $33.73 \pm 6.72$ & 21.00 & 55.00 & $33.37 \pm 6.99$ \\
Calcium $(\mathrm{mg})$ & 345 & 860 & $597.55 \pm 203.51$ & 345.00 & 860.00 & $601.27 \pm 202.75$ \\
Iron $(\mathrm{mg})$ & 3.20 & 15.00 & $6.89 \pm 2.67$ & 3.00 & 15.00 & $6.67 \pm 2.56$ \\
Zinc $(\mathrm{mg})$ & 4.30 & 14.00 & $7.616 \pm 2.42$ & 4.00 & 15.00 & $7.49 \pm 2.34$ \\
\hline
\end{tabular}




\section{Conclusion}

Gender disparity is still prevalent in different aspect of life throughout the world. Though in recent decades, there is a significant advance in gender equality. This study explores health, nutritional status, dietary diversity, nutrient intake by boys and girls in Rajshahi City, Bangladesh. Girl children are nutritional marginalized segment of the society. Increasing social development may help to reduce gender disparity and improve the nutritional status of overall all children. Intervention program of Government for empowering woman and improving equal status to man, weakens and breaks gender disparity as well as helps the country to ensure economic growth.

\section{References}

Alom J, Islam MA and Quddus MA (2009). Socioeconomic factors influencing nutritional status of under-five children of agrarian families in Bangladesh: a multilevel analysis. Bangladesh Journal of Agricultural Economics, XXXII(1\&2): 63-74.

Alam S (2012). The effect of gender-based returns to borrowing on intra-household resource allocation in rural Bangladesh. World Development, 40(6): 1164-1180.

Altman DG (1991). Practical statistics for medical research. London: Chapman and Hall.

Dancer D, Rammohan A and Murray SD (2008). Infant mortality and child nutrition in Bangladesh. Health Economics, 17: $1015-1035$.

De Rose LF, Das M and Millman SR (2000). Does female disadvantage mean lower access to food? Population and Development Review, 26(3): 517-547.

De Schutter O (2013). Gender equality and food security: Women's empowerment as a tool against hunger. Asian Development Bank. http://www.adb.org/sites/default/files/pub/2013/gender-equality-and-food-security.pdf.

Dey I and Chaudhuri RN (2008). Gender inequalities in nutritional status among under five children in a village in Hooghly district, West Bengal. Indian Journal of Public Health, 52: 218 -220.

Ezzati M, Lopez AD, Rodgers A, Vander Hoorn S and Murray CJ (2002). Selected major risk factors and global and regional burden of disease. Lancet, 360: 1347-60.

FAO (2012). The State of Food Insecurity in the World, United Nations. http://www.fao.org.

Hall JG, Allanson JE, Gripp KW and Slavotinek AM (2007). Handbook of Physical Measurements. Oxford University Press, New York.

Harris and Barbara (1990). The intra family distribution in South Asia. Dreze, J. and Sen, A., eds. The Political Economy of Hunger. Oxford, Oxford, clarendon Press, 1: 351-424.

Kennedy G, Ballard T and Dop MC (2010). Guidelines for Measuring Household and Individual Dietary Diversity. Nutrition and Consumer Protection Division, Food and Agriculture Organization of the United Nations.

Kennedy GL, Pedro MR, Seghieri C, Nantel G and Brouwer I (2007). Dietary Diversity Score Is a Useful Indicator of Micronutrient Intake in Non-Breast-Feeding Filipino Children. Journal of Nutrition, 137: 472-477.

Lohman T, Roche AF and Martorell R (1988). Anthropometric Standardization Reference Manual. Chicago: Human Kinetics Publication, Chicago.

MC Williams (1980). Nutritional for growth years. 3 rd edition. USA.

McGregor GS, Cheung YB, Cueto S, Glewwe P, Richter L and Strupp B (2007). Development potential in the fi rst 5 years for children in developing countries. The Lancet, 369 (9555): 60-70.

Moestue H, de Pee S, Hall A, Hye A, Sultana N, Ishtiaque MZ (2004). Conclusions about differences in linear growth between Bangladeshi boys and girls depend on the growth reference used. European Journal of Clinical Nutrition, 58: 725-731. 
Ndiku M, Jaceldo-Siegl K, Singh P and Sabate J (2011). Gender inequality in food intake and nutritional status of children under 5 years old in rural Eastern Kenya. European Journal of Clinical Nutrition, 65: 26-31.

Osman S and Sen A (2003). The hidden penalties of gender inequality: fetal origins of ill-health. Economic and Human Biology Journal, 1: 105-121.

Seetharaman N, Chacko TV, Shankar SLR and Mathew AC (2007). Measuring Malnutrition -The Role of Z Scores and the Composite Index of Anthropometric Failure (CIAF). Indian Journal of Community Medicine, 32(1): 35-39.

Smith LC and Haddad L (2000). Overcoming child malnutrition in developing countries: Past achievements and future choices A 2020 vision for food, agriculture, and the environment. International Food Policy Research Institute: Washington, DC. pp.1-2.

Steyn NP, Nel JH, Nantel G., Kennedy G. and Labadarios D (2005). Food variety and dietary diversity scores in children: are they good indicators of dietary adequacy? Public Health Nutrition, 9: 644-650.

Svedberg P (2000). Poverty and Undernutrition: Theory, Measurement and Policy. Oxford India Paperbacks, New Delhi. UNDP (United Nations Development Programme) (2008): Human development report: 2007-2008, New York: UNDP.

WHO (2012). WHO child growth standards, Length / Height-for-age, weight-for-age, weight-for-length, weight-for-height, body mass index-for-age, Methods and development.

World Bank (2006). Repositioning nutrition as central to development a strategy for large-scale action. Washington DC: USA. Available online at http://siteresources.worldbank.org/NUTRITION.

(Manuscript received on January 06, 2018 and revised on July 07, 2018) 